\title{
Cultural Variation and Teenager's Self-Evaluation and Ingroup Bias
}

\author{
Jiayi Geng \\ ${ }^{1}$ Canadian International School of Hong Kong, 36 Nam Long Shan Road, Aberdeen, Hong Kong \\ *Corresponding author. Email: gracejiayigeng@gmail.com
}

\begin{abstract}
This paper discusses the correlation between cultural variation and humble Chinese teenagers' (15-16 years) selfevaluation and ingroup bias. The two studies in this paper separately discusses the effect of cultural variation on teenagers' self-evaluation and its effects ingroup bias. In Study 1, I studied whether cultural variation (Western and Chinese cultures) would influence the self-evaluation of humble Chinese teenagers. The predicted result shows that participants in the Western Culture Group show an increase in self-evaluation after exposure to Western culture teaching styles in a period of time. In Study 2, the relationship between different self-evaluations and ingroup bias is investigated. The predicted results show that the group with increased self-evaluation has more tendency of having group bias. These results suggest that cultural variation is an influential factor for self-evaluation which also affects the ingroup bias rates.
\end{abstract}

Keywords: teenagers, cultural variation, ingroup bias, self-evaluation.

\section{INTRODUCTION}

This paper is inspired by another research paper that examined the cultural variation of Japanese (Asian representative) and Americans (Western representative), and the correlation between cultural variation, selfesteem and ingroup bias. They have used self-reported survey They concluded that Americans generally have higher self-esteem, so they have higher rates of ingroup bias. [4] However, the methods used in the research are ineffective to test Asians' self-esteem in general as it uses a self-reported question on the statement "I have higher self-esteem than people around me", which potentially has a self-reported bias. Many Asians are generally more humble as they were educated to give themselves a moderate or even lower rating when rating themselves, and there is a teaching style difference among the Asian and Western cultures. Western culture has a more encouraging and positive education style while many Asian culture virtues teach students to be conservative about themselves. [8] Therefore, we modified this procedure of testing self-esteem in a way that is suitable for Asians, especially targeted Chinese, to test an accurate self-evaluation for humble Chinese teenagers, and formed the first study. In addition, instead of including two native groups that represent Western and Asian cultures, included participants all from one country (China) and investigate how cultural variation would affect the participants' self-evaluation in a short term by simply applying Western teaching styles on Chinese students. Moreover, in the same paper, ingroup bias is found related to self-esteem. We wanted to find out whether a change in the self-esteem testing methods would lead to differences in the ingroup bias of higher self-esteem and lower self-esteem individuals. Therefore, Study 2 is included to discuss the relationship between self-evaluation and ingroup bias.

\section{LITERARY REVIEW}

As mentioned in the introduction, Asian and Western countries have varied educational cultures. (As the participants are solely from China, the Asian culture will specifically be referred as Chinese traditional cultures in the paper. ) In China, educational cultures are significantly influenced by Confucian, who had a perspective thinking that individuals need to be constantly improving themselves and remain humble at all times. [9] This thought has integrated in the educational system in China, which is taught to students since they are young. Moreover, teachers often criticize students when scoring low in exams, so the thoughts of "keep humble" are more or less instilled in local Chinese teenagers' minds. On the other hand, the Western culture of education greatly emphasizes compliments and encouragements, even if students did not do so well. They believe that the style of criticizing students would lead to 
the result of students giving up on studying [7]. Therefore, due to the distinct educational styles of China and Western countries, many teenagers who grew in mainland China are considerably more "humble" than teenagers under Western educational influences. Such "humbleness" is sometimes integrated into Chinese students' thoughts, which may lead to distinct results in student's self-evaluation of their own self-esteem in comparison to the students grew up in Western countries. Therefore, the humble style of education might lead to the result of Chinese students grading their selfevaluations lower than their actual ability. Specifically, the "humble" teenagers in this paper would be defined as participants who have self-evaluation lower than their actual ability.

\subsection{Study 1}

In this study, we focus on how Western teaching styles could influence the humble Chinese teenagers' self-evaluation ratings. A specific subject, Mathematics, is chosen to be the field of the experiment in this study. This subject is chosen because it is one of the basic education subjects that students learned since primary school. All participants would be doing regular tests on Mathematics about the knowledge learned in class, as well as self-evaluations about their own thought on how they perform in the subject of Mathematics. We hypothesized that under Western teaching style influences, humble Chinese teenagers would perform a higher rating of self-evaluation than before.

\subsection{Method}

15 to 16 years old local Chinese students (grade 10 students) were included, and are required to take a selfevaluation test on their mathematics abilities by rating their extent of agreement on the statement "My math is better than people around me" using the 1 (strongly disagree) -7 (strongly agree) scale. Then, the actual mathematics grades of these students in their schools (obtained by seeking permission from the school principals and will be kept confidential) are compared to their self-evaluations. Participants that rated themselves lower than their actual ability are considered "humble" $(\mathrm{N}=200)$.

The "humble" participants are randomly assigned into 2 groups, the Chinese Culture Group (CCG) and Western Culture Group (WCG), each consisting of 100 participants. Participants are required to take a normal grade 10 math test, and their test results are recorded. Participants Chinese Culture Group (CCG) are told that there are rooms for improvement and they scored averagely regardless of their test results. Conversely, Western Culture Group (WCG) participants will be encouraged on their test results regardless of their test results and are told that they exceeded the normal expectations. This procedure will repeat every day and last for 2 weeks. After 2 weeks, participants from both CCG and WCG will retake the self-evaluation test (exactly the same format as the previous test), and their self-evaluation rating before and after will be recorded and compared.

There is an imagination of the Local Western Group (LWG) that would take the math test and are taught in the Chinese Traditional teaching styles when giving out results. Then, their self-evaluation ratings before and after the exposure to Chinese teaching styles would be compared to the other 2 groups. This imaginary group might be a further prove that teaching styles will influence students' self-evaluation scores to a certain extent. However, this group would not be included in the actual procedure and is a decent imagination.

\section{RESULTS}

Our prediction suggests that Chinese Culture Group (CCG) participants's self-evaluation ratings would remain the same as their first self-evaluation rating and even a small number of participants' self-evaluation dropped. On the other hand, a large proportion of WCG participants' self-evaluation would increase by a certain amount and a few participants would remain the same. A significant effect of cultural variation on humble Chinese teenagers' self-evaluation can be deduced from this result because the self-evaluations are influenced in only two weeks' time, which if the experiment is done across a longer period of time, greater signs of self-evaluation changes would occur. Moreover, the

\subsection{Study 2}

This study is the extension of Study 1. As the result in Study 1 showed that most participants from Western Culture Group (WCG) practiced an increase in selfevaluation ratings after due to cultural variation effects, we want to examine the relation between self-evaluation sand ingroup bias as well. Therefore, Study 2 discusses whether cultural variation will affect ingroup bias correspondingly to the variation of ingroup bias. Our hypothesis is that the Western Culture Group (WCG) participants who have increased their self-evaluation ratings would have greater ingroup bias than the Chinese Culture Group (CCG) participants who's self-evaluation remained.

\subsection{Method}

Participants in Study 1 will also be participants of Study 2, which are the students that have been put into different groups: Western Culture Group (WCG) and Chinese Culture Group (CCG). All participants from Western Culture Group (WCG) in Study 1 who increased their self-evaluation ratings (e.g. $\mathrm{N}=85$ ) would be renamed as the Increased Self-Evaluation Group (ISEG). 
To ensure both groups have the same number of participants, 85 participants are randomly chosen from Chinese Culture Group (CCG) to participate in Study 2 and are renamed as Remained Self-Evaluation Group(RSEG). Therefore, the total number of participants would be 170 ( 85 ISEG+85 RSEG).

The procedures used in this study are referenced to the inspiration paper that discussed the ingroup bias of cultural variation [5]. Participants would answer an online survey including questions of two kinds: Group identities and Group personality traits. To establish some semblance of connection between the participants and their ingroup before the survey questions, they are told that their similarities made them a group, but the exact reason (increased self-evaluation ratings) would not be explained. They would also be informed that there is another group besides them, and there are differences among the two groups. After the informing the participants of all the regulations and necessary information, the survey would begin, which would be separated into 2 sections:

\subsubsection{Group identities:}

Participants need to complete an 8-item measure of identification with ingroup (4 items) and outgroup (4 items). Items are adapted and modified from previous research that studied ingroup bias [6] [12]. Sample questions include "How much do you identify yourself with your group?" and "To what extent do you feel strong ties with your group?". Then, participants would be using a scale from 1 (none) - 7 (entirely) to answer all 8 questions on the online survey.

\subsubsection{Group personality traits:}

In this section of the survey, the participants are asked to rate 5 characteristics (friendly, rude, hard-working, considerate, and lazy ) using the scale from 1(strongly disagree) to 7 (strongly agree) of both the ingroup and outgroup that do not include the participant himself/herself. The same questions would be asked for both the ingroup and outgroup. These characteristics include 3 positive words and 2 negative words, the participants' answers to these questions will consider the rate of their ingroup and outgroup bias. For example, if the participant answers strongly agree to a question associated with positive words about the group that they are in, this is considered as a trait of ingroup bias. This rate for ingroup bias or outgroup bias is dependent on the number that they rate themselves in regarding to the questions that they are answering. The rate of 7 (strongly agree) suggests that the participant has a strong ingroup or outgroup bias on a particular question that they are answering. The example questions include, "given the statement my group/the other group is friendly, rate your agreement towards this statement from 1 to 7". These are similar measures used in previous research to test the groups' self-enhancement [5]. In this paper, it is used to examine the participants rate of ingroup bias or outgroup bias.

\section{RESULTS}

The predicted result is that the Increased SelfEvaluation Group (ISEG) would display a stronger pattern of ingroup bias than the Remained SelfEvaluation Group (RSEG) on both Group identification and Group personality traits categories. This is because the Increased Self-Evaluation Group (ISEG) generally giver higher ratings to their ingroup when answering questions associated with positives words. Moreover, they tend to give slightly lower ratings to similar questions related to their outgroup. In general, participants in this group might give stronger ratings to answer all questions in our predicted results, such as more $7 \mathrm{~s}$ and $2 \mathrm{~s}$. Contrarily, the Remained SelfEvaluation Group (RSEG), which consists participants that did not increase their self-evaluations show less ingroup bias. Their ratings of both their ingroup and outgroup, and questions using both positive and negative words are generally more moderate. This might means that they give more numbers in the middle of the scale, such as $4 \mathrm{~s}$ and $5 \mathrm{~s}$. The results here shows that the rate of ingroup bias that participants have is also dependent of the self-rated evaluations that they give themselves. Therefore, we conclude that teenagers having a higher self-evaluation rating overall would have a greater tendency of developing ingroup bias than teenagers who have a lower self-evaluation rating [3] [7].

\section{LIMITATION AND EXTENSION}

In study 1, we concluded that cultural variation should affect the self-evaluation of participants based on research. Moreover, we attempted to influence the selfevaluation of participants from China by having them being exposed to Western cultures for 2 weeks. However, there are possibilities that the original culture and background are too strong that the self-evaluation would not be influenced. This is because participants lived and exposed to their original Chinese traditional culture for 15-16 years, 2 weeks of education is only a temporary change in teaching style and may not be long enough to influence the self-evaluation of these students since the original culture is so deep-rooted. Moreover, despite having changes in self-evaluations in the survey, we cannot conclude that the self-evaluation is completely influenced by the cultural difference and the different education styles that both cultures because there are other factors that might influence this as well, such as the difficulty of the tests and peer pressure. In addition, not all Chinese students have the "humble" style of education, so the participants result in study 1 may not be applicable to and represent all Chinese students. However, as the majority of students are being taught under the "humble" 
of style of education, it is still used to be a representation of the Chinese education style.

In Study 2, there are also possibilities that no patterns of ingroup bias would be shown in the Increased SelfEvaluation Group and Remaining Self-Evaluation Group. This is because the personal preference and characteristics of each participant are different, some may have ingroups or outgroups due to various reasons, but not solely on self-evaluation differences. These reasons could include their past experiences, the participants' familiarity of the other participants in their own group and the other group etc. Therefore, there might be no obvious patterns to the correlation between the self-evaluation and ingroup bias tendency, which is a limitation to my study results.

\section{CONCLUSION}

From the results of Study 1 and Study 2, the overall finding is that humble Chinese students' self-evaluations are affected by Western teaching styles due to cultural variation, in which the self-evaluation differences among the teenagers would also influence their ingroup bias ratings. According to the predicted result in study 1, western teaching styles of education would generally encourage students and lead to overall high selfevaluation scores whereas students under Chinese teaching styles would have a lower self-evaluation score. Chinese students who are influenced by the western teaching style, the Western Culture Group (WCG) in this study, generally perform greater ingroup bias. Therefore, a relation between ingroup bias and self-evaluation is drawn, in which teenagers who perform a higher selfevaluation, according to the predicted results in study 2 . These results could possibly give a better understanding of how cultural variation impacts self-evaluation and therefore affects the ingroup bias as a whole.

\section{REFERENCES}

[1] C.L. Aberson, M. Healy, \& V. Romero, Ingroup Bias and Self-esteem: A Meta-analysis. Personality and Social Psychology Review, 4(2), 2000, pp. 157-173. DOI: https://doi.org/10.1207/S15327957PSPR0402_04

[2] A. Hassan, N.S. Jamaludin, Approaches \& Values in Two Gigantic Educational Philosophies: East and West, http://community.dur.ac.uk/p.b.tymms/oerj/publicat ions/9.pdf

[3] J. Crocker, I. Schwartz, Prejudice and Ingroup Favouritism in a Minimal Intergroup Situation: Effects of Self-esteem, Personality and Social Psychology Bulletin, 1985, 11(4), pp. 379-386. DOI: https://doi.org/10.1177/0146167285114004
[4] C.F. Falk, S.J. Heine, K. Takemura, Cultural Variation in the Minimal Group Effect, Journal of Cross-Cultural Psychology, 2013, 45(2), pp. 265 281.

DOI: https://doi.org/10.1177/0022022113492892

[5] C.F. Falk, S. J. Heine, M. Yuki, K. Takemura, Why Do Westerners Self-enhance More Than East Asians? European Journal of Personality, 2009, 23(3), 183203. DOI: https://doi.org/10.1002/per.715

[6] P. G. Grieve, M. A. Hogg, Subjective Uncertainty and Intergroup Discrimination in the Minimal Group Situation, Personality and Social Psychology Bulletin, 1999, 25(8), 926-940. DOI: https://doi.org/10.1177/01461672992511002

[7] S. J. Heine, T. Hamamura, In Search of East Asian Self-enhancement. Personality and Social Psychology Review, 2007, 11(1), 4-27. DOI: https://doi.org/10.1177/1088868306294587

[8] R.B. Iyer, Blending east and west for holistic education. Academic Journals, 2015, 10(3), 244-248. DOI: https://doi.org/10.5897/ERR2014.2015

[9] J. Li, (2016). Humility in learning: A Confucian perspective. Journal of Moral Education, 147-165. https://doi.org/10.1080/03057240.2016.1168736

[10] Y. Wang, Research on Confucian Family Education Thought, 2017 , http://cdmd.cnki.com.cn/Article/CDMD-107301017713999.htm

[11] Y. Xie, G. Chen, Confucius' thoughts on Moral Education in China [PDF], Cross-Cultural Communication, 2013, 9(4), 45-49. DOI: https://doi.org/10.3968/j.ccc.1923670020130904.2 659

[12] T. Yamagishi, N. Mifune, J.H. Liu, J. Pauling, Exchanges of Group-based Favours: Ingroup Bias in the Prisoner's Dilemma Game with Minimal Groups in Japan and New Zealand. Asian Journal of Social Psychology, 2008, 11(3), 196-207. DOI: https://doi.org/10.1111/j.1467-839X.2008.00258.x 